may influence the effect of BCG as an anti-tumour agent in experimental tumour models in which BCG is given to stimulate the immune system. ${ }^{3}{ }^{4}$ Mackowiah $^{5}$ describes the use of different microorganisms or their products, or both, for immunotherapy and immunoprophylaxis in malignancies in man and animals. The use of antigens of $E$ granulosus in this way might be an interesting subject for future research.

1 Yong WK, Heath DD, Savage T. Possible antigenic similarity between pulmonary carcinoma and cysts of Echinococcus granulosus. $\mathrm{Br} \mathrm{Med} \mathcal{F}$ $1979 ; \mathrm{i}: 1463-4$

2 Varela-Diaz VM, Coltorti EA, D'Allesandro A. Immunoelectrophoresis tests showing Echinococcus granulosus arc 5 in human case of Echinococcus vogeli and cysticercosis-multiple myeloma. Am f Trop Med Hyg 1978; 27:554.

${ }^{3}$ Borsos T, Rapp HJ. Antigenic relationship between Mycobacterium bovis (BCG) and a guinea-pig hepatoma. $\mathcal{F}$ Natl Cancer Inst 1973;51:1085-6.

4 Bucana C, Hanna MG. Immunoelectronmicroscopic analysis of surface antigens common to Mycobacterium bovis (BCG) and tumor cells. $\mathcal{F} \mathrm{Natl}$ Cancer Inst 1974;53:1313-8.

5 Mackowiah PhA. Clinical uses of microorganisms and their products. Am $\mathcal{F}$ Med 1979;67:293-306.

(Accepted 15 April 1980)

Section of Parasitology, Laboratory for Pathology, National Institute of Public Health, PO Box 1, 3720 BA Bilthoven, the Netherlands F VAN KNAPEN, MD, head of section

\section{Transluminal dilatation of transplant renal artery stenosis}

Surgical attempts to revascularise the kidney in patients with renal artery stenosis after transplant are frequently unsuccessful. ${ }^{1}$ Several recent reports show good results from transluminal angioplasty in spontaneous renal artery stenosis. ${ }^{2}{ }^{3} \mathrm{We}$ report the result of transluminal angioplasty in a patient in whom arterial stenosis developed in a transplanted kidney.

\section{Case report}

An 18-year-old woman had a cadaver renal transplant in February 1979 (renal artery anastomosed end-to-end to the left internal iliac artery). She had had haemodialysis since July 1975 and bilateral nephrectomy and ureterectomy were performed in September 1975 for intractable hypertension and ureteric reflux. Blood pressure remained at $150 / 90 \mathrm{~mm} \mathrm{Hg}$ until six weeks after transplantation, when it rose to $150 / 110 \mathrm{~mm} \mathrm{Hg}$; treatment was started with methyldopa and propranolol. In May 1979 a bruit was noted over the left iliac fossa, and a renal arteriogram showed $85 \%$ stenosis in the left renal artery distal to the suture line; transluminal dilatation of the stenosis was attempted. To obtain measurements of plasma renin concentration, the anti-hypertensive drugs were discontinued. Three days later her blood pressure had risen to $212 / 126 \mathrm{~mm} \mathrm{Hg}$ and bethanidine (20 $\mathrm{mg}$ a day) was started.

A 9-French gauge double-lumen catheter, with a balloon of external diameter $6 \mathrm{~mm}$ and a length of $1.5 \mathrm{~cm}$, was used for angioplasty. Dilatation of the stenosis by the femoral route failed because the sharp angulation of the patient's aortic bifurcation prevented the catheter passing to the desired site. Axillary puncture was also unsuccessful and the procedure was abandoned. We attempted further dilatation two weeks later, introducing the catheter via a left subclavian arteriotomy. Bethanidine was stopped 12 hours before dilatation, when blood pressure was $160 / 104 \mathrm{~mm} \mathrm{Hg}$. After infusing the renal artery with heparinised saline, the vessel was dilated several times and the stenosis was reduced from $85 \%$ to $40 \%$ (figure). Some irregularity of the intima was then seen. Thereafter, intravenous infusion of heparin (5000 units $/ 6 \mathrm{~h}$ ) was given for 24 hours. After a single dose of warfarin $(10 \mathrm{mg})$ haematuria was noted and warfarin discontinued. When the macroscopic haematuria resolved 72 hours later dipyridamole $(300 \mathrm{mg} /$ day) was begun. One hour after dilatation blood pressure was $160 / 126 \mathrm{~mm} \mathrm{Hg}$, and bethanidine $10 \mathrm{mg}$ twice daily was given for 48 hours. Blood pressure fell and 24 hours later was $116 / 90 \mathrm{~mm} \mathrm{Hg}$. Immediately after the procedure the bruit was no longer evident. Two days later, the patient had pain in the left iliac fossa with fever of $38^{\circ} \mathrm{C}$. Urine showed many red blood cells and a few white cells. No organisms were identified in urine or blood. The patient's blood pressure was $110 / 80 \mathrm{~mm} \mathrm{Hg}$ and bethanidine was stopped. The abdominal pain and fever settled over $\mathbf{4 8}$ hours. The urine was clear of cells after seven days. Nine days after the procedure blood pressure was $120 / 80 \mathrm{~mm} \mathrm{Hg}$ lying and $140 / 80 \mathrm{~mm} \mathrm{Hg}$ standing, without antihypertensive drugs. The patient was then discharged home on prednisolone $12.5 \mathrm{mg} /$ day, azathioprine 125 $\mathrm{mg} /$ day, and dipyridamole $300 \mathrm{mg} /$ day.

Plasma renin concentration was $36 \mathrm{mU} / 1$ (normal 9-50 $\mathrm{mU} / \mathrm{l}$ ) before the procedure, and 34 and $32 \mathrm{mU} / 124$ hours and six days afterwards. Total exchangeable sodium measured just before the procedure gave a value of 1974 $\mathrm{mmol}(\mathrm{mEq}) / \mathrm{l}$ and a repeat estimation one week later gave a value of 1800
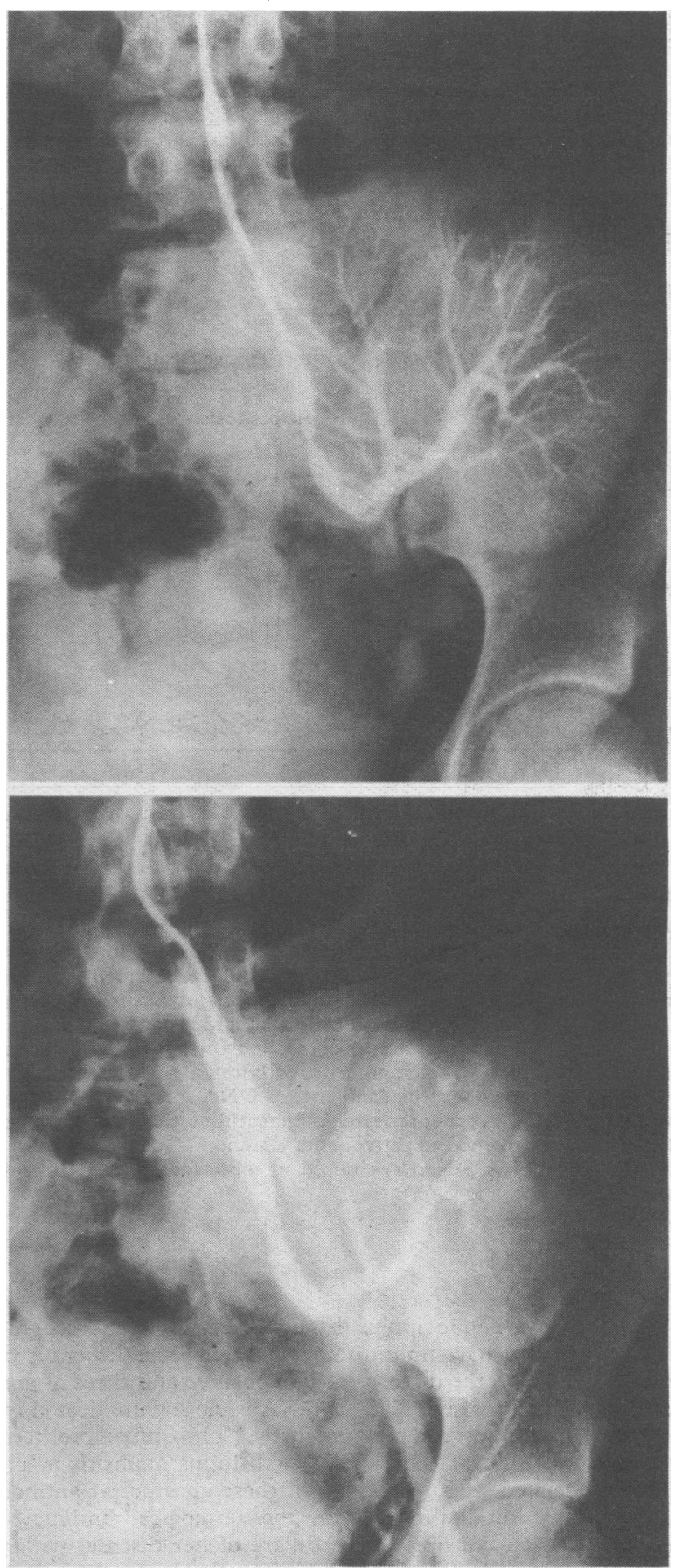

Pretreatment arteriogram (top) showing $85 \%$ stenosis in transplant renal artery. Postdilatation arteriogram (bottom) shows stenosis reduced to $40 \%$ with intimal irregularity which normally heals satisfactorily. 4 Postdilatation radiograph shows slightly earlier phase than pretreatment arteriogram, thus accounting for apparent lack of intrarenal vasculature.

mmol/l (normal range 1800 to $2080 \mathrm{mmol} / \mathrm{l}$ ). Creatinine clearance was 69 $\mathrm{ml} / \mathrm{min}$ before the procedure; 48 hours afterwards creatinine clearance had fallen to $24 \mathrm{ml} / \mathrm{min}$ but seven days later had risen to $53 \mathrm{ml} / \mathrm{min}$.

Eight months later, the patient remained well with no audible bruit over the left iliac fossa. Blood pressure was $140 / 90 \mathrm{~mm} \mathrm{Hg}$ lying and 130/90 mm $\mathrm{Hg}$ standing, without antihypertensive treatment. Renal function was still slightly reduced, with a creatinine clearance of $57 \mathrm{ml} / \mathrm{min}$. 


\section{Comment}

Normal blood pressure has been restored by transluminal angioplasty. Renal function was impaired after the angioplasty and was due to either extensive manipulation of the catheter or injection of radio contrast medium. ${ }^{5}$ Renal function subsequently returned close to pre-procedure levels. The reduced blood pressure coincided with, and may have been due to, a reduction in total exchangeable sodium, although external sodium balance was not measured. In patients with transplants who develop renal artery stenosis, it may be worth using this technique rather than surgery, which has a high failure rate and associated morbidity.

1 Osborne DE, Castro JE, Hackman R. Surgical correction of arterial stenosis in renal allografts. Br $\mathcal{F}$ Urol 1976;48:221-6.

2 Gruntzig A, Vetter W, Meier B, Kuhlmann V, Lutolf V, Siegenthaler W. Treatment of renovascular hypertension with percutaneous transluminal dilatation of a renal-artery stenosis. Lancet $1978 ; \mathrm{i}: 801-2$

${ }^{3}$ Katzen BT, Change J, Lukowsky GH, Abramson EG. Percutaneous transluminal angioplasty for treatment of renovascular hypertension. Radiology 1979;131:53-8.

${ }^{4}$ Mahler F, Krneta A, Haertel M. Treatment of renovascular hypertension by transluminal renal artery dilatation. Ann Intern Med 1979;90:56-7.

${ }^{5}$ Older RA, Miller JP, Jackson DC, Johnsrude IS, Thompson WM. Angiographically induced renal failure and its radiographic detection. Am F Roentgenol 1976;126:1039-45.

(Accepted 15 April 1980)

\section{Western Infirmary, Glasgow}

D CARR, MRCP, FRCR, consultant, $x$-ray department

R O QUIN, MD, FRCS, consultant, department of surgery

D N H HAMILTON, PHD, FRCS, consultant, department of surgery

J D BRIGGS, MB, FRCP, consultant, renal unit

B J R JUNOR, MD, MRCP, consultant, renal unit

P F SEMPLE, MB, MRCP, consultant, MRC blood pressure unit

\section{Myopericarditis associated with farmer's lung}

Farmer's lung is an extrinsic allergic alveolitis caused by mouldy hay. ${ }^{1}$ Its main immunological mechanism is considered to be the immune-complex-mediated (type III) reaction. ${ }^{2}$ Local injury in the alveoli and bronchioles seems to be the predominant feature of the disease. $^{3}$ Abnormality in other organs, however, has not been described, even though patients with farmer's lung also have systemic complaints such as malaise, fever, and various aches and pains.

We report a case in which myopericarditis was associated with farmer's lung.

\section{Case Report}

A 35-year-old farmer, who was an ex-smoker and otherwise healthy, suffered a clinically proved episode of farmer's lung for the first time in late autumn 1976. All the symptoms cleared within six months. In early spring 1978 he suffered a relapse. A chest radiograph showed a slight increase in the size of the heart when compared with earlier radiographs. Relative heart volume measured from the radiograph, however, was still normal $\left(450 \mathrm{ml} / \mathrm{m}^{2}\right)$. Five months later the volume was above normal $\left(510 \mathrm{ml} / \mathrm{m}^{2}\right)$. He had no hypertension, an electrocardiogram was normal, and there were no clinical signs of cardiac failure. At catheterisation of the right side of the heart with pressure measurements, in September, both pulmonary arterial and pulmonary wedge pressures were normal. In December he suffered a second relapse. No further increase in heart size was seen. A resting electrocardiogram was normal, but during exercise a prominent $P$ wave was seen which did not disappear until 10 minutes after exercise. There was no chest pain.

The patient tried to avoid further exposures to mouldy hay, but one evening in May 1979 he worked without a dust respirator for about one and a half hours in a cow shed. That night he had severe shortness of breath, coughed up blood-stained sputum, and had fever and muscular pains. Two days later he was admitted to hospital, where cardiac failure with tachycardia and ventricular gallop rhythm was diagnosed. No pericardial friction rub was heard. Electrocardiograms showed negative $T$ waves in limb leads and left chest leads, and several days later also in right chest leads. There was no laboratory or clinical evidence of myocardial infarction.

Erythrocyte sedimentation rate was $12 \mathrm{~mm}$ in first hour and blood leucocyte count $11.9 \times 10^{9} / 1\left(11900 / \mathrm{mm}^{3}\right)$ with $7 \%$ eosinophils; otherwise the differential count was normal. Tests for LE cells, antinuclear antibodies, and rheumatoid factor were negative. Antistreptolysin titre and antiviral antibody titres to common respiratory pathogens and complement-fixing antibody titres to Mycoplasma pneumoniae were normal. Cold agglutinins were not found. A precipitin test to Thermoactinomyces vulgaris gave a positive result. The urine was normal. A chest radiograph showed an enlarged heart shadow (relative volume $655 \mathrm{ml} / \mathrm{m}^{2}$ ); pulmonary venous congestion and interstitial pulmonary oedema were also visible. Echocardiography showed an enlarged left ventricle, low ejection fraction, and pericardial effusion. The patient was given digitalis, diuretics, and corticosteroids. The worst symptoms disappeared rapidly. Two weeks later echocardiography showed no pericardial effusion but the function of the left ventricle was still impaired. Over the next few months the heart remained dilated and electrocardiographic signs of left ventricular hypertrophy and strain persisted. In January 1980 function of the left ventricle was still impaired.

\section{Comment}

The repeated episodes of farmer's lung suggest that this patient was highly sensitive to moulds. He developed cardiac enlargement gradually with the relapses of alveolitis. Catheterisation excluded pulmonary hypertension as the cause of the enlargement. Drastic deterioration of cardiac function with acute failure and pericarditis occurred several hours after exposure to vegetable dusts, strongly suggesting a causal relation between exposure and cardiac deterioration. Pericarditis alone was not responsible for the failure; repeated check-ups showed that there was also permanent myocardial injury.

That in this case the myopericarditis might have been a manifestation of the farmer's lung syndrome, caused by circulating immune complexes, seems worthy of consideration. Cardiological examination of all patients with extrinsic allergic alveolitis might help to detect other cases of a similar nature.

We thank the Academy of Finland for financial support.

Requests for reprints should be addressed to Dr Erkki O Terho, University Central Hospital, Kuopio, SF-71880 Tarinaharju, Finland.

1 Pepys J. Hypersensitivity diseases of the lungs due to fungi and organic dusts. Monogr Allergy 1969;4:72-99.

2 Pepys J. Immunopathology of allergic lung disease. Clin Allergy 1973;3: $1-22$.

3 Ghose T, Landrigan P, Killeen R, Dill J. Immunopathological studies in patients with farmer's lung. Clini Allergy 1974;4:119-29.

(Accepted 15 April 1980)

\section{University Central Hospital, Kuopio, Finland}

ERKKI O TERHO, MD, department of pulmonary diseases

RISTO VALTA, MD, department of pulmonary diseases

HANNU TUKIAINEN, $M D$, department of pulmonary diseases

ESKO LÄNSIMIES, MD, department of clinical physiology

\section{Purpuric rash due to epsilon-aminocaproic acid}

Epsilon-aminocaproic acid (EACA) is now widely used to prevent rebleeding after subarachnoid haemorrhage. Side effects and complications $^{1-4}$ include diarrhoea, toxic confusional states, arterial and venous thrombosis, and pulmonary embolism. We report a case in which a purpuric morbilliform rash was due to treatment with EACA.

\section{Case report}

A woman aged 59 years was admitted to hospital with sudden onset of severe headache and loss of consciousness. A similar headache three weeks before had been followed by dysphasia for a few hours. On admission she was deeply unconscious with neck stiffness and decorticate posture. Computed tomography showed intraventricular and subarachnoid bleeding. She was treated conservatively and given EACA $24 \mathrm{~g}$ daily in divided dosage through a nasogastric tube. Her condition remained unchanged and after 12 days she developed a morbilliform rash over the front and sides of the chest and in the axillae. Some of the lesions became purpuric. She was not then on any other drug. EACA was discontinued and the rash completely disappeared within 72 hours. A full blood count was normal but detailed coagulation studies were not done. On further challenge after two months with EACA (6 g sixhourly) she again developed a faintly erythematous rash (not purpuric this 